\title{
ECOBANNER: REAPROVEITAMENTO SUSTENTÁVEL DE LONAS VINÍLICAS
}

\author{
Leticia Hermes \\ UNIVILLE \\ lethermes@gmail.com \\ Elenir Carmen Morgenstern \\ UNIVILLE \\ elenir.m@gmail.com
}

Resumo: $O$ presente resumo apresenta o desenvolvimento do projeto de Iniciação Científica, intitulado "Ecobanner", proposta vinculada ao Projeto de Extensão AmaViva (Amadurecer e Viver: associando saberes na UNIVILLE), em parceria com a Secretaria de Assistência Social de Joinville e Departamento de Design da UNIVILLE (Universidade da Região de Joinville). A referida pesquisa objetivou investigar, em termos teóricos e práticos, possibilidades de desenvolvimento de artefatos ambientalmente amigáveis que, por meio da aplicação de ferramentas do campo do design e reuso de banners descartados pela UNIVILLE, auxiliem na visibilidade dos projetos de pesquisa e extensão da própria universidade. A metodologia empregada, fundada em referentes teóricos do campo do design englobou: pesquisa bibliográfica, pesquisa visual, experimentações, desenvolvimento de projeto de produto, capacitação do grupo produtor por meio de workshops, execução de artefatos pelas integrantes do Projeto AmaViva, comercialização dos produtos. Por meio de ferramentas de projeto do campo do design, como brainstorming, pesquisa qualitativa e quantitativa, análise de parâmetro, análise de relação produto-usuário, geração de alternativas, imersão, prototipagem, etc, possibilitou-se o desenvolvimento e aprimoramento de técnicas para o manuseio e criação de novos produtos a partir do reuso de lonas de banner descartadas pela própria universidade. Como principais resultados do projeto, destacam-se: a) produtos desenvolvidos e informações adquiridas, ao final da pesquisa repassados ao projeto de extensão AmaViva, por meio de oficinas de capacitação, estimulando a ação sustentável, agregando saberes e técnicas de design ao grupo e promovendo a geração de trabalho e renda; b) assentos sustentáveis modulares, com reaproveitamento de lonas do GAMPI (evento anual do departamento de design da universidade) foram produzidos e dispostos para uso, no ambiente universitário, desenvolvidos em parceria com os projetos AmaViva e Univille em Ação. Entende-se que a pesquisa Ecobanner, em suas ações, promoveu a sustentabilidade na universidade, a consciência ambiental e a geração de trabalho e renda entre os agentes relacionados ao projeto, explorou novas alternativas de matéria prima para a produção de design, possibilitou a interação da 
pesquisa e extensão na academia e configurou-se em incentivo para desenvolvimento de novas pesquisas na área.

Palavras-chave: design, sustentabilidade, geração de renda. 